\title{
Manuel Bandeira: imagem, poesia, pintura
}

\author{
Laíse Ribas Bastos ${ }^{1}$ \\ Universidade Federal do Rio de Janeiro, Rio de Janeiro, RJ, Brasil
}

Resumo: A proposta deste trabalho é investigar a relação entre poesia e pintura a partir da crítica de arte de Manuel Bandeira, tendo em vista a sensibilidade aguda do poeta para a tradição moderna da poesia e das artes plásticas no Brasil. A leitura crítica de Bandeira acerca da pintura, bem como seu exercício de poeta, indicam que o trabalho com a imagem está para além daquela que se forma, exclusivamente, no âmbito de um domínio visual e representativo. Transitando quase indistintamente entre um campo artístico e outro, ao poeta e ao crítico interessará, na poesia ou na pintura, o pensamento com a imagem cuja possibilidade de apreensão ocorre por meio de uma conjugação de sentidos e sensações, sem necessariamente um "suporte de significação", nos termos de Jean-Luc Nancy (2016).

Palavras-chave: Poesia; pintura; Manuel Bandeira.

Title: Manuel Bandeira: image, poetry, painting

Abstract: The objective of this work is to investigate the relationship between poetry and painting based on Manuel Bandeira's art criticism, considering the poet's acute sensitivity to the modern tradition of poetry and visual arts in Brazil. Bandeira's critical reading of painting (mainly in the chronicles published after the 1940s), as well as his practice as poet, indicate that the work with the image is beyond the one is formed exclusively from a visual and representative domain. Almost indistinctly transiting between one artistic field and another, in poetry or painting, the poet and the critic will be interested in the thought with the image whose possibility of apprehension occurs through a combination of senses and sensations, without necessarily a "support of meaning", in the words of Jean-Luc Nancy (2016).

Keywords: Poetry; Painting; Manuel Bandeira.

Em 1941, Manuel Bandeira começa a escrever sistematicamente crítica de artes plásticas para o jornal carioca $A$ manhã, o que poderia evidenciar o quanto sua obra pode abrir-se a um pensamento orientado por seus escritos sobre arte, pensamento igualmente percebido em seus textos sobre música e sobre literatura. Essa abertura ocorre para além da própria poesia e de seu Itinerário de Pasárgada, texto amparado pela fluidez, entre autobiografia e memória, ensaio, reflexão crítica e testemunho, entre a subjetividade do poeta e o fazer literário. A amplitude de sua produção revela um aspecto peculiar e, no

\footnotetext{
${ }^{1}$ Professora de Literatura Brasileira no Departamento de Letras Vernáculas da Universidade Federal do Rio de Janeiro (UFRJ). Doutora em Literatura pela Universidade Federal de Santa Catarina (UFSC). Orcid: https://orcid.org/0000-0001-5550-7499 E-mail: laisebastos@letras.ufrj.br
} 
mínimo, instigante, do seu percurso de poeta, justificado, de certo modo, pelo sujeito conduzido pelas significativas transformações e mudanças de sensibilidade implicadas na transição entre os séculos XIX e XX.

Apesar da colaboração regular para o jornal na década de 1940, os "escritos sobre arte" de Manuel Bandeira estão presentes ao longo de toda sua produção periodística, inclusive aquela anterior à coluna de $A$ manhã. Além de apontarem para o percurso do poeta-crítico, nos moldes (e temas) do que posteriormente expressariam Joaquim Cardozo, João Cabral de Melo Neto e mesmo Carlos Drummond de Andrade, seus textos guardam, sobretudo, a expressão e o olhar afeitos à modernidade, lembrando, em certa medida, as reflexões presentes nos textos de Charles Baudelaire sobre os salões de arte ou sobre a Exposição Universal de 1855, por exemplo. Baudelaire nos leva a um percurso sobre as obras, para, em seguida, pousar olhar e pensamento em um foco específico. Bandeira, por sua vez, na maioria das vezes motivado pelas exposições de um artista ou mesmo pelos salões de arte, sobre os quais se obrigava a escrever e acompanhar, nos coloca diante de uma grande porta aberta para as artes, que pressupõe a pintura e a literatura como procedimentos o tempo todo em-relação, como se o poeta se perguntasse a partir deles: qual lição?

Em uma crônica de 1933, intitulada "Romances" e publicada em O Estado de Minas, Bandeira analisa o procedimento de escrita de Amando Fontes, político e escritor nascido em São Paulo e que viria a falecer um antes do poeta, e cujo primeiro livro, Os corumbás, recém havia sido publicado naquele ano. Bandeira afirma que o romance era rico em "dados objetivos" capazes de enaltecer a capacidade de "observação ativa e aguda, sem esforço", numa narrativa cheia de "interesse, paixão e expectativas" (2009b, p. 75), e que aguardava a publicação de algo capaz de reter a "totalidade da nossa vida num dado momento" (2009b, p.75). O mais interessante, talvez, não esteja nas poucas linhas dedicadas a comentar a escrita de Amando Fontes, e sim, nestas que seguem. Afirma Bandeira:

\footnotetext{
Temos imaginação, mas falta-nos a fantasia. [...] "Fantasia" deriva de phantazo, verbo que significa fazer aparecer, mostrar na realidade, representar sob tal ou qual aparência, figurar ${ }^{2}$. Fantasia será, pois, a imaginação, quando cabe exteriorizar e dar corpo ao seu conteúdo. Temos fantasia para representar uma vida, algumas vidas. [...]

E cabe perguntar: será por falha fundamental da capacidade criadora ou simples vício de composição, falta de aplicação ou ausência de estímulo? (2009, p. 73-74)
}

Para Bandeira, ainda, a pura imaginação guardaria a aptidão para reproduzir "no espírito as sensações, na ausência das causas exteriores que as provocaram; e a fantasia, capacidade de organizar as imagens na unidade de uma obra" (2009b, p. 73). Ao destrinchar etimologicamente o termo fantasia, Bandeira nos leva ao entendimento dessa capacidade criadora como exposição e figuração (então ausente nos romancistas brasileiros). O poeta tende a procurar em nossos artistas esse ímpeto imaginativo e algum projeto que o coloque

\footnotetext{
${ }^{2}$ Dicionário grego-francês de Alexis Chassang (1827-1888)
} 
em cena, como quando constata "a fantasia de Cícero Dias" (2009b, p.358), o "pintor-poeta" (2009b, p. 363) e reconhece em algumas de suas obras o escape das formas de animais em imagens quase inomináveis. Uma dessas observações aparece na crônica "Exposição Segall", também de 1933:

Segall animalista mostra decidida preferência pelos bois. Aqui é interessante notar a influência de Cícero Dias. Todavia não chega à abstração do pintor pernambucano, que pinta os animais de tal maneira que a gente quase não os pode nomear, vaca, burro, cachorro ou peixe - são "bichos", e nisso se mostra bem brasileiro. (2009b, p.146)

Bandeira salienta ainda, na mesma crônica, que Cícero Dias, em suas pinturas, é sempre poeta - e talvez aí já possamos vislumbrar um esboço de uma lição entre poesia e pintura.

A "capacidade criadora", derivada da imaginação, conforme identifica Bandeira, nos leva às reflexões de Baudelaire, especialmente no "Salão de 1859", quando o poeta assinala a primazia da "musa extravagante" (isto é, a imaginação) sobre todas as outras faculdades humanas: "Ela alcança todas as outras; excita-as e envia-as ao combate", diz Baudelaire (1988, p. 75). E depois, arremata: "Todas as faculdades da alma humana devem subordinarse à imaginação, que as requisita simultaneamente" (1988, p. 84). As afirmações de Baudelaire permitem entender que são insuficientes a existência e o desenvolvimento da inteligência, perspicácia, domínio da técnica e dos meios artísticos se não houver capacidade de imaginação.

Indo adiante da percepção romântica sobre a imaginação, Baudelaire afirma que a "rainha das faculdades" caracteriza-se pela análise, pela síntese e pela sensibilidade ${ }^{3}$. A capacidade de imaginar define-se, então, por um movimento de associação e oscilação entre contrários, movimento sob o qual o homem pode decompor elementos para reorganizá-los de acordo com outras regras - aquela capacidade que Bandeira exige dos romancistas brasileiros. Nesse sentido, a própria ideia de fantasia evocada por Bandeira estaria associada ao sentido de imaginação criadora, conforme pensada por Baudelaire, para quem, ainda, "foi a imaginação que ensinou ao homem o sentido moral da cor, do contorno, do som e do perfume" (1988, p. 76), lembrando a analogia e a metáfora, resultados dessa capacidade de gerar imagens e figuras. A "imaginação criadora" estaria no polo oposto de qualquer forma ou tentativa de representação exata da realidade, no entanto, também seria uma função

\footnotetext{
${ }^{3}$ Para Shelley, a imaginação ocorre apenas pela capacidade de síntese, em oposição à logizein, princípio da análise, portanto, da razão. A imaginação é configurada na ação da mente sobre os pensamentos, para pintá-los com sua própria luz, desse modo compondo outros pensamentos - algo que ele denomina poiein, o princípio da síntese: "Esta é poiein, ou o princípio da síntese, e tem como seus objetos aquelas formas que são comuns à natureza universal e à própria existência". De acordo com Shelley, ainda, "A razão respeita as diferenças e a imaginação, a semelhança das coisas". (SHELLEY, 2008, p. 77).
} 
distinta da fantasia ${ }^{4}$. Na simbiose poesia-pintura, a lição é ir além do que se vê, despertar a capacidade de desfiar sentidos e sensações a partir da imagem - seja ela um esboço, um gesto ou uma tentativa de captar ou sugerir um instante. Eugène Delacroix é, pois, um dos pintores que mais o impressionam, justamente pela capacidade de criar um estado de movimento e caos - vale lembrar, caos esse submetido a um princípio organizativo. A apreensão da agitação, da expressividade de um gesto ou sensação, o que é "tumultuoso e tranquilo como depois de um grande acontecimento", são atributos do poeta-pintor nas palavras de Baudelaire, como se fosse uma tarefa única - a poesia-pintura -, a mesma atribuída por Manuel Bandeira a Cícero Dias e seus animais disformes.

Para Baudelaire,

Uma qualidade, muito grande, imensa, do talento de Delacroix, que faz dele o pintor amado pelos poetas, é que ele é essencialmente literário. [...] E observem bem que jamais é pela afetação, minúcia ou dissimulação de métodos que Delacroix atinge esse prodigioso resultado; mas antes pela harmonia, a combinação profunda, completa entre cor, tema e o desenho, e pela dramática gesticulação de suas figuras. (1988, p. 57)

Assim, toda imagem se enche de alguma forma de vida ou movimento. Afirma ainda Baudelaire: "quanto mais ela [a imaginação] estiver apoiada, mais será poderosa" (1988, p. 77), indicando que, por meio do respaldo de outras faculdades e habilidades, é possível ampliar a capacidade e os efeitos da imaginação. Dispor do que ele denomina como um "reservatório de observações" seria um dos modos de apoiar e respaldar efetivamente a imaginação. Lembremos que a capacidade de observar está expressa naquilo que é próprio de seu sentido etimológico, "advertência, prática" (CUNHA, 2007, p. 555), e, também, "espreitar", "espiar", ou, ainda, "considerar com atenção" (HOUAISS, 2009), o que implica, consequentemente, inclinar-se a algo com atenção e com intenção. Essa perspectiva irá designar também uma atitude não passiva no ato de guardar e, principalmente, de apreender e estar atento a uma cena, a um instante, a algo ou alguém. Visão que irá nortear certo procedimento poético do próprio Bandeira, como aquele mesmo olhar lançado sobre a maçã pousada tão simples no quarto de hotel, e detalhadamente estudado por Davi Arrigucci Jr. em "Ensaio sobre maçã" (1990) bem como em O cacto e as ruínas (2000), neste último apontando diretamente a importância das artes plásticas para a configuração da poesia de Bandeira no contexto de uma tradição moderna da poesia no Brasil.

Retomemos a lição. Para Bandeira, serão a potência imaginativa e a inteligência permanentemente desafiada os principais critérios na leitura e recepção dos novos pintores.

\footnotetext{
4 A "fantasia", para Baudelaire, "é tanto mais perigosa quanto mais fácil e aberta; perigosa como a poesia em prosa, como o romance [...]; perigosa como toda liberdade absoluta. [...] Aqui, portanto, não há mais analogia, apenas o acaso; mas, ao contrário, há confusão e contraste, um campo disparatado devido à ausência de uma cultura regular" (1988, p. 107). É nítida, portanto, a diferença no entendimento da noção de fantasia por Bandeira, que parece estar mais próxima da "imaginação criadora" pensada por Baudelaire, ou a "potência criadora", a "imaginação que dá corpo ao seu conteúdo", nos termos do próprio Bandeira.
} 
É o que leva o poeta, por exemplo, a desdenhar, em certo momento, a fase antropofágica de Tarsila do Amaral, afirmando que eram quadros como "Religião Brasileira", "Anjos", "Pastoral", aqueles "verdadeiramente difíceis de explicar, porque a intervenção da inteligência atrapalha" (2006, p. 195). Basta o olhar e o exercício de memória e imaginação desenrolados a partir da imagem, embora, segundo Bandeira, sejam imagens com "o mínimo de deformação plástica", reveladoras de "observação sutil e profunda" (2006, p. 195) ecoando, mais uma vez, o que afirmara Baudelaire: "a imaginação, graças à sua natureza compensadora, contém o espírito crítico" (1988, p. 79).

É também essa capacidade criadora que o leva a encontrar em Portinari um de seus pintores preferidos e, igualmente, a admirar a obra de outro pintor então menos conhecido, José Pancetti. Isso porque não seriam repetidores: Pancetti não repetia Portinari, que não repetia Picasso. Bandeira identifica em Pancetti o que ele chama de "originalidade forte e espontânea", pintor de "tons baixos, tristes e francos", de desenho "direto e despojado" (2009, p. 257). E, desse modo, refazendo a lição, afirma, em "Grandes perdas", crônica de 1958, por ocasião da morte do pintor:

Pancetti, que era sobretudo um pintor, sentia de vez em quando necessidade de se exprimir em versos, como se o amor em que todo se abrasava - amor pelas mulheres, pela poesia, pela paisagem, pelo mar, que foi a sua constante paixão, não pudesse caber nas cores e nos volumes dos seus quadros. [...] Pancetti apareceu forte, fresco, fecundo, sem nada que nem de longe lembrasse o pintor de Brodowsky. Não lembrava ninguém. O seu grande mestre foi o mar. [...] em Pancetti o que havia era, como já disse, a paixão do mar, principalmente do mar nas suas horas de soberana tranquilidade, o mar dos profundos azuis, cujo segredo de melancolia o pintor soube fixar com a mão segura. (2009a, p. 924-925)

O pintor de Brodowsky era Portinari, cuja influência Bandeira afirma ter se tornado "uma praga na pintura nacional" (2009a, p. 925). Portinari que, por sua vez, encontrara meios de expressar o que havia de brasileiro e pessoal em sua arte, libertando-se também da influência que teve por algum momento da pintura de Picasso. Essas são algumas das razões que levariam Bandeira a gostar tanto da série de Portinari sobre sua cidade natal, além da parcela de vida pequena, movimento, descontração e leveza infantil e despretensiosa nela presentes.

De alguma forma percebe-se, portanto, que, para Bandeira, a inquietação do artista deve pautar sua arte, o que se estabelece também como busca. São esses elementos que, segundo ele, faltariam à pintura de Presciliano Silva, artista "sem novidade, seguro de sua sensibilidade e satisfeito com a técnica anterior a Cézanne" (2009b, p.268). Nesse momento, deixando falar o sujeito do século XX e evocando Cézanne, Bandeira parece apontar para a mesma inquietação e pupila aguda que Joaquim Cardozo, em 1926, identificava também no

\footnotetext{
${ }^{5}$ Nessa mesma crônica, intitulada "Tarsila antropofágica", Bandeira comenta a fase então mais recente de Tarsila, de certo modo acusando-a de ter feito "voto de pobreza" em seus últimos quadros, o que teria deixado Oswald - "pajé da tribo", segundo ele - e os antropófagos radiantes (2006, p. 196).
} 
pintor francês, "esperando que os primeiros raios de luz do dia a nascer penetrassem no interior da Catedral de S. Giorgio, em Veneza, para sentir todo aquele interior deslumbrante reviver, surgir da sombra envolvente tomando novas formas que só ele àquela hora surpreendeu". (CARDOZO, 2007, p. 509). Importante lembrar, mais uma vez, o ensaio de Davi Arrigucci quando analisa o procedimento de Cézanne a partir da still life, a qual tende a realçar o procedimento e a unidade formal do tema, em cenas de vida imobilizadas, sem "sucessão linear da realidade empírica" e reorganizando o espaço (1990, p. 27). Como se vê, Cézanne, em certa medida, desdobra Baudelaire e será um pintor importante no entendimento da arte moderna e sua relação com a poesia para Joaquim Cardozo, Manuel Bandeira e, mais adiante, João Cabral de Melo Neto.

João Cabral também aponta o duplo procedimento - retomando a lição de Bandeira - em pelo menos dois poemas que indicam diretamente a natureza ambígua da poesia e da pintura. O poeta, que, em certa ocasião, afirmara que o poema era para ele "como se pintasse um quadro" (2008, p. XXXIV), assinala em sua "Lição de pintura", de Museu de tudo, um modo de fazer o poema pautado pelo constante inacabamento, ou pela sua possibilidade de permanente continuidade. Essa abertura e liberdade de composição pautam também, conforme lembra Davi Arrigucci (1990), o procedimento de Cézanne em seus exercícios de forma, cor e volume na still life. E em "Lição de poesia", de $O$ engenheiro, Cabral extrai o processo de composição do poema da materialidade dos objetos até sua evaporação. Dito de outra forma, na experiência moderna, extrai da amplitude de possibilidades da pintura a sua lição para a poesia, em sua noção de permanente processo.

O procedimento pode parecer um pouco ao revés do realizado por Bandeira, que deixa sempre claro o fato de não ser crítico de arte e de não se reconhecer como tal, quando diz, por exemplo, não entender nada de artes plásticas, em uma crônica intitulada exatamente "Não entendo nada de artes plásticas", de 1941 (2009b); ou ainda, quando afirma "não tenho nenhuma autoridade para aconselhar ninguém", ao falar da obra de Ismailovitch (2009b, p.271). As afirmações soam quase como uma mise-en-scène, fazendo de Bandeira um personagem de si mesmo, como já anotara Ana Cristina Cesar (1999) ao comentar a atuação de Bandeira em "O poeta do castelo" (1959), de Joaquim Pedro de Andrade, descolando a figura do sujeito-autor daquela do poeta-personagem. As declarações de Bandeira adquirem, porém, certa autoridade e uma função inversa, especialmente quando sua lição é a que estamos percorrendo: ler na pintura sempre uma lição de poesia.

Alguns poemas de Manuel Bandeira apresentam-se como exercício acerca da materialidade das formas e das superfícies, da objetividade das coisas e do jogo com o olhar. São poemas em que, embora presente, o sujeito acaba inserindo-se sutil e gradativamente, como vemos em "Gesso", poema de $O$ ritmo dissoluto, publicado em 1924:

Esta minha estatuazinha de gesso, quando nova - O gesso muito branco, as linhas muito puras Mal sugeria imagem da vida (Embora a figura chorasse). 


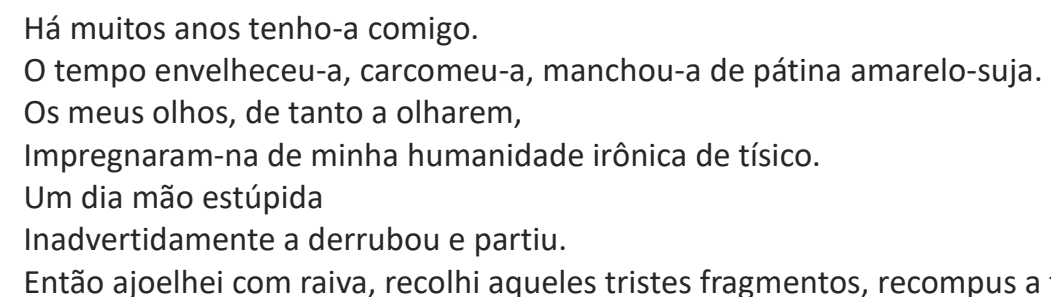
E o tempo sobre as feridas escureceu ainda mais o sujo mordente da pátina... [que chorava.

Hoje este gessozinho comercial

É tocante e vive, e me fez agora refletir

Que só é verdadeiramente vivo o que já sofreu.

(1993, p. 117)

Neste poema, a esterilidade e a artificialidade insinuados pela superfície branca e lisa do gesso encontram-se inevitavelmente contaminadas logo nos primeiros versos, com uma sugestão de vida na imagem estática: um esboço de choro impresso na estátua a evocar também a dor de Laocoonte, presente no poema "O cacto", de Libertinagem, 1930; ou então, quase como o sujeito que sai de casa de brim branco engomado, e ao cruzar a primeira esquina é sujo de lama por um caminhão que passa, em "Nova poética", de Belo belo, 1948: "É a vida" (1993, p.205), diz um verso espacialmente deslocado no poema. De alguma maneira, a estátua de gesso vai, aos poucos, se preenchendo de vida: a fixidez do olhar a contamina com a humanidade de um sujeito que a recompõe e a observa, guardando em si a mesma capacidade de observação igualmente parte do processo de uma imaginação criadora. Logo, a vida que surge ali é irônica, uma humanidade às avessas ou quase sarcástica nas linhas dos versos que se alongam após a queda - da estátua no chão, e do poema no universo da prosa, ambos recolhidos nos três versos finais. Uma noção de tempo também atravessa a superfície do gesso por meio da figuração do choro, do processo de deterioração que lhe atinge, de sua queda estúpida, até sua possível recomposição no gesto drummondiano de tentar colar os fragmentos da estátua (como os cacos de xícara do aparador na "lição de coisas" de Drummond). Ao recompor a estátua, o sujeito recompõe também o choro e, consequentemente, "a marca suja" da vida que aparece em "Nova poética" - "Poeta sórdido:/aquele em cuja poesia há a marca suja da vida" (BANDEIRA, 1993, p. 205) - é aqui um pedaço de vida fragmentária. Uma vida qualquer e padronizada (a estatuazinha comercial) figurada na sóbria e artificial superfície de gesso ${ }^{6}$. Há um tempo, portanto, presente no poema, e sua força incisiva não está na lágrima inexpressiva da figura estática, e sim no amarelo-sujo, no carcomido do gesso até que este se quebre, até que haja

\footnotetext{
${ }^{6}$ Novamente, difícil não lembrarmos das afirmações de Baudelaire diante da indústria fotográfica e sua tentativa de reprodução fiel da natureza, refúgio de "todos os pintores fracassados, sem talento ou demasiado preguiçosos para concluírem seus esboços": "Não será permitido pensar que um povo cujos olhos se acostumam a considerar os resultados de uma ciência material como os produtos do belo não diminuiu singularmente, ao cabo de um certo tempo, a faculdade de julgar e de sentir o que há de mais etéreo e mais imaterial?" (1988, p. 74).
} 
uma assimilação possível entre sujeito e estátua, quando ela pode, também, lhe devolver algo.

É possível perceber o exercício imagético, ainda, no poema "A realidade e a imagem", de Belo belo, em um reflexo equívoco formado no chão seco após a chuva, quando o passeio das pombas se sobrepõe à imagem do arranha-céu que desce ao chão.

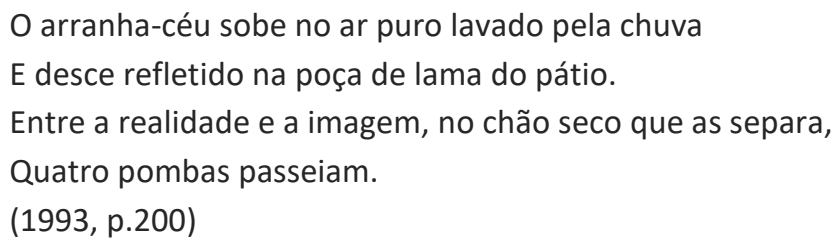

Diante da imagem - na superfície da pintura ou no poema -, o movimento de Bandeira parece indicar uma consciência de sua força e de sua distinção, muito perto dos termos pensados por Jean-Luc Nancy (2016) ao analisar o distinto da imagem (da música à pintura, da poesia ao cinema). Nancy afirma que

\footnotetext{
O que deve ser compreendido é o modo como a força e a imagem pertencem uma à outra inclusive na distinção, como a imagem se oferece através de um traço distintivo (toda imagem se declara ou indica-se "imagem" de alguma maneira) e como aquilo que ela oferece é, antes de tudo, uma força, uma intensidade, a própria força de sua distinção. (2006, p. 98)
}

A lição de Bandeira, tomada entre a poesia e a pintura, movimenta-se, assim, em direção ao traço distintivo da imagem, de onde emana sua força e intensidade. A imagem, conforme pensada por Jean-Luc Nancy, não se caracteriza pela sua capacidade representativa e tampouco seria "suporte de uma significação" (2016, p. 107). Ela é impressão do íntimo e sua paixão, como lembra Nancy, e - importante destacar - sua força tende aquém ou além das formas (2016, p. 98). A mesma força e espontaneidade identificada em Pancetti, por exemplo, quando cores e volumes não dariam conta da paixão inicial da imagem ou exatamente no azul profundo dos seus quadros nos quais Bandeira encontra também a fixação de um "segredo de melancolia".

Esse tratamento dado à imagem evidencia notadamente a intensidade natural e inapreensível da imagem poética - como se vê no arrebatamento da estatuazinha de gesso (quase esvaziado no artefato comercial), ou na sutileza entre uma realidade tangível e uma imagem do arranha-céu na poça de lama do chão lavado após a chuva. Apesar de tamanha fluidez, o poema encerra ainda o movimento das pombas sobre o alto edifício refletido no chão. Conforme enfatiza Nancy, na poesia, mais do que metáfora, analogia ou símbolo, a imagem é deslocamento, choque de sentido e som que se produz: "A imagem é tudo isso ao menos: ela está no corte do verso e no descolamento da língua, está na suspensão do ritmo e da atenção, está nesse "fundo" [...] no qual a poesia torna-se ela mesma matéria da imagem". (2016, p. 107) 
Mafuá do malungo, publicado em 1948, é um livro dedicado a João Cabral de Melo Neto e por ele impresso em sua prensa manual quando residia na Espanha, "magro poeta e arquiteto" como consta na dedicatória da primeira edição (em sua missiva, Bandeira algumas vezes se referia a Cabral como "poeta arquiteto"). No livro, as reflexões de Bandeira reaparecem em forma de poema. Em "Balanço de março de 1959", menciona a exposição neoconcreta do Museu de Arte Moderna do Rio de Janeiro, e revela um sujeito com certo desconforto diante dos novos artistas, especialmente, diante dos questionamentos impostos nas novas obras: a ampliação da tela, a ausência da moldura: com Lígia "aprendi, mas não vi pintura" (1993, p. 333), diz o poema. Porém, com Ferreira Gullar, lemos: "Uma palavra só e em torno/Muito branco basta a Gullar/Para um belo poema compor/No estilo mais oracular" (1993, p. 333), quando aparenta encontrar a linha de fuga (ou o branco, o espaço e escape onde ainda haveria lugar para o poema).

Bandeira não esconde um olhar cuidadoso também diante da poesia concreta, como deixa claro nas constantes justificativas e explicações em algumas crônicas sobre o assunto publicadas no final da década de 1950. Apesar de suas rápidas incursões pela poesia concreta, parece que a noção do entorno para Bandeira permite o entendimento também de uma forma de pensar a lição - poesia e pintura. A atenção passa a se voltar para os possíveis elementos ou forças atrativas que estejam fora do quadro ou do próprio poema, como se o poeta indagasse ao espectador-leitor acerca do que está em volta, para além do contorno, do que está dito ou é visto. E nesse outro exercício perceptivo são evocadas sensações, cores, gestos, memórias, a partir do tratamento dado a cada cena colhida - seja no quadro ou no poema (a pequena estátua de gesso já fazia este anúncio).

No entanto, Bandeira possui uma maneira distinta daquela de Cabral, por exemplo, para lidar com as relações entre os dois modos de composição, estabelecendo uma perspectiva que coloca poesia e pintura em-relação e em permanente trânsito. Trata-se do olhar de poeta lendo o quadro e repensando procedimentos da pintura, sem propor exatamente uma "teoria" desenvolvida a partir de um estudo, como Cabral afirma ter encontrado em Miró7. A busca e predileção por tentar captar o elemento poético de cada pintura evidencia, também, uma horizontalização entre um e outro modo de expressão. De certa forma, é o que está implicado na leitura que faz dos desenhos de Presciliano Silva (para Bandeira, de expressividade superior em relação à pintura): "bom desenhista", de “impressão agradável quando a arte serve à poesia” (2009b, p. 268).

$\mathrm{Na}$ mesma direção, estaria a alegação do seu suposto desconhecimento sobre artes plásticas, o que enfatiza a inclinação poética do crítico de arte, presente também na imagem de um "poeta menor", como se autodenomina na crônica sobre o catálogo da série Amazônia, de Maria Martins. Ao comentar as fotografias do catálogo, Bandeira pensa o possível diálogo entre Cobra Norato, de Raul Bopp, e as imagens das esculturas de Maria Martins, de quem elogia a forma "intencionalmente rude" e a "sugestão desmesurada e

\footnotetext{
7 "Miró sempre me interessou muito pelo o que imaginei ser sua teoria da composição. Mas, como pintor, me interessa mais um Mondrian, um Malevitch, um Albers, os construtivistas em geral" (CABRAL, 2008, p. XXXIV).
} 
caótica" (2009b, p. 407). Entretanto, a mise-en-scène do crítico talvez assinale muito mais o empreendimento de uma tarefa poética para as artes e o aparente desejo de nelas encontrar, de algum modo, a inevitável "marca suja da vida".

Um pouco mais distante da objetividade sóbria das coisas e do olhar estático sobre a realidade, pode-se dizer que o exercício crítico de Bandeira desdobra-se entre o prisma de Baudelaire e o que diz Nancy, ao sublinhar que a imagem é uma força: uma "função de imagem, que está para além daquela que imaginamos a partir unicamente do estímulo visual - ela é "musical, poética, táctil, olfativa ou gustativa, cinestésica", etc. (NANCY, p. 100). Um equilíbrio instável se faz vislumbrar entre potência criadora, realidade e imaginação; entre a impassibilidade ou imutabilidade da imagem (domínio visual) e seu arrebatamento da separação (domínio audível), nos termos de Nancy - sua força, capacidade de ser pega, penetrada (e não sua forma). No poema ou na pintura, sua instabilidade pode estar, portanto, nos modos de apreensão da vida comezinha, na precisão da técnica e na mínima deformação plástica traduzidos na radicalidade de Maria Martins; na expressão da vida de homem do mar dos quadros de Pancetti; na vida sugerida e na memória desfiada nos quadros de Tarsila e Portinari ou, mesmo, no "equilíbrio plástico" e na "emoção poética de uma técnica limpa, sóbria, sem afetações nem facilidades" (2009b, p. 327) de Guignard (que ilustraria a primeira edição dos poemas traduzidos de Bandeira, em 1945).

\section{Referências}

ARRIGUCCI JUNIOR, Davi. Humildade, paixão e morte: a poesia de Manuel Bandeira. 2. ed. São Paulo: Companhia das Letras, 1990.

ARRIGUCCI JUNIOR, Davi. O cacto e as ruínas: a poesia entre outras artes. São Paulo: Duas Cidades/Ed. 34, 2000

BANDEIRA, M. Crônicas da província do Brasil. 2. ed. São Paulo: Cosac Naify, 2006.

BANDEIRA, Manuel. Poesia completa e prosa. 5. ed. Rio de Janeiro: Nova Aguilar, 2009a

BANDEIRA, Manuel. Crônicas inéditas 2, 1930-1944: Manuel Bandeira. São Paulo: Cosac Naify, 2009b

BANDEIRA, Manuel. Estrela da vida inteira. 20. ed. Rio de Janeiro: Nova Fronteira, 1993.

BANDEIRA, Manuel. Itinerário de Pasárgada. 3. ed. Rio de Janeiro: Nova Fronteira; Brasília: INL, 1984.

BAUDELAIRE, Charles. A modernidade de Baudelaire: textos inéditos. Org. Teixeira Coelho. Trad. Suely Cassal. Rio de Janeiro: Paz e Terra, 1988.

CARDOZO, Joaquim. Sobre a pintura de Teles Júnior. Poesia completa e prosa. Rio de Janeiro/Recife: Nova Aguilar/Massangana, 2007. p. 509-517

CESAR, Ana Cristina. Desafinar o coro. Crítica e tradução. São Paulo: Ática, 1999, p. 57-70.

CUNHA, Antônio Geraldo da. Dicionário etimológico da língua portuguesa. Rio de Janeiro: Lexikon, 2007, p. 555. 
HOUAISS eletrônico, ver.3.0, 2009. [Dicionário Houaiss da língua portuguesa]

MELO NETO, João Cabral de. Poesia completa e prosa. 2. ed. Rio de Janeiro: Nova Aguilar, 2008.

NANCY, Jean-Luc. A imagem - o distinto. Trad. Carlos E. S. Capela. Outra travessia. Florianópolis, n. 22, 2016, p.97-109.

SHELLEY, Percy Bysshe. Uma defesa da poesia e outros ensaios. Trad. e notas Fabio Cyrino e Marcella Furtado. São Paulo: Landmark, 2008.

Recebido em: $X X / X X / 20 X X$ Aceito em: $X X / X X / 20 X X$ 